\title{
Clases sociales, sectores económicos y cambios en \\ la estructura social chilena \\ entre 1992 y 2013
}

\author{
Pablo Pérez Ahumada ${ }^{1}$
}

\section{Resumen}

Según investigaciones recientes, una característica central de la sociedad chilena es su mesocratización, es decir, el crecimiento sostenido de la clase media. En este artículo se prueba empíricamente dicha tesis. A partir del modelo de clases de Erik O. Wright y la técnica del análisis de la porción de cambio (shift-share analysis), se estudiaron los cambios en la estructura de clases chilena en los períodos de 1992 a 2003 y de 2003 a 2013, y se concluye que la idea de mesocratización es cuestionable. Entre 1992 y 2013, el número de personas ubicadas en posiciones de clase media es sustantivamente inferior al de personas de clases populares (clase trabajadora y de autoempleados informales). Además, el crecimiento de la clase media ha sido relativamente marginal y ha estado acompañado de tendencias que contradicen la idea de una sociedad mesocrática (por ejemplo, el crecimiento de la clase trabajadora entre 2003 y 2013).

\section{Palabras clave}

Estructura social, clases sociales, clase media, clase obrera, medición, análisis económico, Chile

\section{Clasificación JEL}

A14, C80, J21

\section{Autor}

Pablo Pérez Ahumada es Profesor Asistente del Departamento de Sociología de la Universidad Alberto Hurtado, Chile. Correo electrónico: pperez@uahurtado.cl.

\footnotetext{
1 El autor agradece el apoyo que brindó a este estudio el Centro de Estudios de Conflicto y Cohesión Social (COES) (FONDAP/15130009) y los comentarios de Erik O. Wright y Alejandro González, que en diversas etapas del trabajo proporcionaron importantes observaciones.
} 


\section{Introducción}

La transformación de la estructura de clases de las sociedades capitalistas avanzadas fue analizada, durante varias décadas, desde la perspectiva de dos tesis contrapuestas. Por un lado, diversos analistas pusieron de relieve el advenimiento de una sociedad posindustrial, poscapitalista o programada, lo que significaba la consolidación de una gran clase media que fue definida como una de las clases principales del capitalismo de la segunda mitad del siglo XX (Bell, 1973; Dahrendorf, 1959; Touraine, 1971). Estos autores interpretaron dicho fenómeno como el resultado de la desproletarización del proceso de trabajo posindustrial; es decir, como consecuencia del modo en que dicho proceso comenzó a requerir una fuerza de trabajo más calificada, con mayores niveles de conocimiento técnico y autonomía. Algunos incluso señalaron que tales transformaciones darían origen a una "nueva clase" que alteraría significativamente los patrones de constitución del trabajo asalariado (Mallet, 1975; Touraine, 1971).

En contraposición a este punto de vista, otros analistas presentaron una imagen del desarrollo capitalista centrada en el concepto de "proletarización". A partir del célebre trabajo de Harry Braverman (1998), muchos argumentaron que la transformación de la estructura de clases de la segunda mitad del siglo XX expresaba más bien una tendencia conforme a la cual los trabajadores asalariados tenderían a perder el control sobre el proceso de trabajo, así como a desarrollar labores altamente rutinarias y controladas "desde arriba" (Wright y Singelmann, 1982).

Estas dos interpretaciones divergentes dieron origen a una serie de investigaciones empíricas que presentaron resultados muchas veces contradictorios (Crompton y Jones, 1984; Marshall y Rose, 1988; Wright y Martin, 1987; Wright y Singelmann, 1982). En décadas recientes, parte importante de estos debates fue utilizada para examinar las transformaciones de la estructura de clases de naciones menos industrializadas. En estas investigaciones se analizó cómo el desarrollo económico y la inserción en los mercados globalizados de países como la República de Corea, la Provincia China de Taiwán y Turquía transformaron sus estructuras de clases (Kaya, 2008; Koo, 1990; Sen y Koo, 1992).

Los debates sobre las tesis posindustrial y de la proletarización no han tenido un correlato directo en el análisis reciente de las estructuras de clases de América Latina y, más específicamente, de Chile. Sin embargo, gran parte de los argumentos en disputa han sido reproducidos de una $u$ otra manera en las últimas décadas. Así, desde los años noventa, en muchas investigaciones se ha afirmado la existencia de un proceso de mesocratización de la estructura de clases de América Latina en general y de Chile en particular (Franco, Hopenhayn y León, 2010; Hopenhayn, 2010; León y Martínez, 2007; Ruiz y Boccardo, 2015). Dicho fenómeno estaría dado, según estas investigaciones, por el crecimiento sostenido de posiciones de clase media, que tienen niveles medio-altos de calificación o están investidas de autoridad dentro del proceso productivo, es decir, posiciones de "expertos", supervisores o gerentes. Recientemente, sin embargo, en algunos estudios se ha puesto en duda dicha idea, pues se señala que la terciarización de la economía no ha significado, al menos en el caso de Chile, un crecimiento exponencial de la clase media ni un debilitamiento de las barreras de clase tradicionalmente observadas en el país (Gayo, Méndez y Teitelboim, 2016).

Este artículo tiene por objeto contribuir a este debate mediante un análisis de las transformaciones recientes de la estructura de clases chilena. A partir de los elementos básicos del esquema de clases neomarxista propuesto por Erik O. Wright (1985 y 1997) y la técnica del análisis de la porción de cambio, se pretende testear empíricamente la tesis relativa a que el crecimiento de la clase media es una de las características importantes, si no la central, del cambio estructural observado en la sociedad chilena. Sobre la base de datos de la Encuesta de Caracterización Socioeconómica Nacional (CASEN) y la Encuesta Nacional de Empleo, Trabajo, Salud y Calidad de Vida de los Trabajadores y Trabajadoras en Chile (ENETS), se estudian los cambios ocurridos en la estructura de clases en los períodos de 
1992 a 2003 y de 2003 a 2013. El análisis permite concluir que la idea de una sociedad cada vez más mesocratizada es cuestionable. Los datos indican que si bien algunas posiciones de clase media crecieron entre 1993 y 2013, este crecimiento fue débil. Además, durante el período de 2003 a 2013, estuvo acompañado de un aumento de la cantidad de personas empleadas en posiciones de clase trabajadora, que es, en términos absolutos, el más grande si se consideran los dos períodos estudiados.

\section{Transformaciones de la estructura de clases chilena}

En las últimas décadas, el cambio de la estructura de clases ha sido objeto de múltiples estudios. En ese sentido, tanto en Chile como en América Latina en general gran parte de las investigaciones se han centrado en el estudio de la clase media (Castellani y Parent, 2011; Espinoza, Barozet y Méndez, 2013; Franco, Hopenhayn y León, 2011; Gayo, Méndez y Teitelboim, 2016; Gayo, Teitelboim y Méndez, 2013; López-Calva y Ortiz-Juárez, 2014; Ruiz y Boccardo, 2015). En ellas se ha sostenido ampliamente la idea de una estructura social cada vez más mesocratizada, esto es, con una clase media cada vez más grande. Dicha mesocratización de la estructura de clases se ha explicado comúnmente en función del crecimiento del empleo no manual y de los niveles de ingreso de gran parte de la población ocupada (Franco, Hopenhayn y León, 2011; Franco y León, 2010; Hopenhayn, 2010).

En su análisis de la sociedad chilena de mediados de los años ochenta, Arturo León y Javier Martínez (1987) defendieron esa idea con el argumento de que la expansión del sector no manual de servicios se tradujo en un sostenido crecimiento de la clase media en el país. Según estos autores, el proceso implicó tanto mayores posibilidades de ascender a posiciones de clase media como el desmantelamiento de las antiguas culturas obreras centradas en el trabajo industrial (León y Martínez, 2007, pág. 312). La tesis de la mesocratización ha sido profundizada últimamente en las investigaciones de Ruiz y Boccardo (2015), quienes analizaron las transformaciones de la estructura de clases chilena a partir de una actualización de la matriz de categorías sociales desarrollada por León y Martínez.

Sobre la base de este esquema, Ruiz y Boccardo afirman que la sociedad chilena ha mostrado un crecimiento constante de los sectores medios asalariados de "calificación media y alta", empleados fundamentalmente en la burocracia privada de servicios (2015, págs. 64 y 65). Los autores notan que dicho proceso ha sido reforzado por una expansión de la educación superior en el país, que ha permitido la llegada de nuevos contingentes de trabajo calificado, así como por el crecimiento sostenido de "sectores medios gerenciales" que "se fortalecen al alero del pujante sector financiero o primario exportador" y que cuentan con un mayor estatus que "los grupos medios de antaño" ligados a la actividad estatal (2015, pág. 112).

Desde una perspectiva complementaria, otras investigaciones han revelado que tanto la región en su conjunto como diversos países (entre ellos Chile) han experimentado incrementos importantes de los niveles de movilidad social ascendente, entendida como la transición entre un origen de clase trabajadora manual hacia un destino de clase media no manual (do Valle Silva, 2007; Espinoza, 2006; Jorrat, 2005; Palomino y Dalle, 2012; Solís, 2005; Torche, 2014). Sobre la base de esta idea, Torche (2005) describió la sociedad chilena como "desigual pero fluida", atendiendo a los significativos niveles de movilidad intergeneracional existentes entre las posiciones bajas (trabajadores manuales) y medias (trabajadores no manuales) de la estructura de clases.

En Chile, la tesis sobre este proceso de mesocratización no se ha reducido a la descripción de cambios objetivos de la estructura de clases, sino que también ha sido usada para interpretar la debilidad de los actores de clases tradicionales como la clase trabajadora industrial. Así, diversos 
analistas han señalado que el crecimiento de la clase media es una de las principales tendencias estructurales que explican la consolidación de valores meritocráticos entre los asalariados y, producto de ello, la debilidad del movimiento sindical ligado al trabajo industrial (León y Martínez, 2007, pág. 312; Ruiz y Boccardo, 2015, pág. 135). De manera similar, otros investigadores han afirmado que la mesocratización de la estructura de clases se ha traducido en la consolidación de una estructura social en que la noción de "lucha de clases" ha sido reemplazada por una de "lucha por estatus" (Espinoza, Barozet y Méndez, 2013, pág. 180; Franco y León, 2010, págs. 72-74).

Como se ve, la tesis de la mesocratización se centra en relevar dos procesos interrelacionados. Por un lado, se pone de manifiesto la existencia de una clase media en constante crecimiento y enlazada a actividades ocupacionales con niveles medios y altos de calificación, empleada fundamentalmente en el sector privado y de servicios. Por otro, desde esta perspectiva también se destaca la existencia de identidades de clase media que no solo se han consolidado entre los asalariados del sector privado y de servicios, sino que también han generado fuertes barreras subjetivas entre dichos asalariados de "cuello blanco" y los trabajadores manuales (industriales) clásicos.

\section{Análisis críticos de la mesocratización en Chile}

En los últimos años algunos elementos centrales de esta tesis han sido objeto de debate. Atendiendo a los aspectos subjetivos de la noción de mesocratización, algunas investigaciones recientes sobre conciencia de clase en Chile han puesto en duda la idea de que el trabajo comúnmente definido como de clase media (trabajo no manual en sectores de servicios como comercio y finanzas) produzca inevitablemente identidades e intereses diferentes a aquellos de los trabajadores manuales o industriales (Pérez-Ahumada, 2017).

De modo similar, Gayo, Méndez y Teitelboim (2016) analizaron los patrones de gusto y consumo cultural y concluyeron que, en oposición a la idea de una sociedad de clase media, la estructura social chilena contiene barreras de clase simbólicas y culturales que siguen siendo bastante persistentes (Gayo, Méndez y Teitelboim, 2013). Estos autores también han afirmado que algunas variables tradicionalmente asociadas al estudio de la desigualdad (por ejemplo, los recursos económicos, la educación y la ocupación) son factores determinantes de las diferencias que existen en las prácticas culturales de los chilenos. A partir de lo anterior, Gayo y sus colaboradores infieren que, si bien Chile ha experimentado la terciarización de su estructura ocupacional, ella no se ha traducido en la emergencia de una sociedad menos polarizada ni económica ni culturalmente. Esta conclusión es de vital importancia para evaluar si la sociedad chilena es efectivamente una sociedad de clase media. En efecto, en línea con lo afirmado por exponentes del análisis de clase (Crompton, 1993; Oesch, 2006; Wright, 1985), este hallazgo pone en duda la idea de que la expansión del sector de servicios se traduzca necesariamente en el crecimiento de la clase media.

Este tipo de investigaciones ha significado un gran aporte al debate sobre la mesocratización en Chile, que ha estado cargado de complejidades asociadas, entre otras cosas, a la difícil delimitación del concepto de "clase media", así como a la poca disponibilidad de datos que permitan construir esquemas de clase teóricamente fundamentados que ayuden a definir empíricamente dicho concepto (Crompton, 1993). Esto explica en parte que muchos estudios sustenten sus hallazgos y conclusiones en definiciones variadas de lo que se entiende por "clase media"; por ejemplo, definiciones que reflejan la posición de los individuos o familias en el segmento medio de la distribución de ingresos, su ubicación intermedia en los deciles o quintiles de ingreso, o una inserción ocupacional o posición simultánea en escalas ocupacionales y de ingresos determinadas (Barozet y Fierro, 2011; Castellani y Parent, 2011; Franco, Hopenhayn y León, 2011; Franco y León, 2010; Gayo, Teitelboim y Méndez, 2013; León y Martínez, 2007; Lora y Fajardo, 2013; Ruiz y Boccardo, 2015). 
A pesar del uso de definiciones a veces dispares entre sí, estas investigaciones han contribuido de manera sustancial al análisis de la estructura de clases. Especialmente significativo ha sido el aporte, en el caso de Chile, de las investigaciones sustentadas en esquemas de clase teóricamente fundamentados, como los trabajos de Gayo, Méndez y Teitelboim (2016) basados en la obra de Bourdieu (1984) o el estudio de Torche (2005) derivado del modelo de Erikson y Goldthorpe (1992). A partir de enfoques utilizados en la literatura sociológica contemporánea, al examinar la estructura de clases de Chile estos trabajos han añadido una dimensión comparativa que permite comprender de mejor manera las particularidades del caso chileno.

\section{Objetivo de la investigación, esquema de análisis e hipótesis}

Siguiendo la línea de las investigaciones teóricamente fundamentadas, este trabajo tiene por objeto contribuir al estudio de la estructura de clases en Chile sobre la base del esquema de clases neomarxista propuesto por Erik O. Wright (1985 y 1997). A partir de ese esquema, en este artículo se examina empíricamente la afirmación básica, y por ello central, de la tesis de la mesocratización, a saber: que existe un crecimiento sostenido de la clase media, el cual ha generado una estructura de clases claramente mesocratizada. Con datos de la encuesta CASEN y de la Encuesta Nacional de Empleo, Trabajo, Salud y Calidad de Vida de los Trabajadores y Trabajadoras en Chile (ENETS), se analizan las transformaciones de la estructura de clases chilena acaecidas entre 1992 y 2003 y entre 2003 y 2013. Además, se pretende contribuir al análisis de las clases en Chile mediante una técnica estadística poco utilizada pero muy relevante para el estudio del cambio de la estructura de clases: la técnica del análisis de la porción de cambio. Como se mostrará más adelante, esta técnica permite identificar las fuentes de cambio que explican las transformaciones observadas en la estructura social (particularmente, las fuentes asociadas a la transformación de los sectores económicos y a la composición de clases dentro de cada sector económico).

Junto con el modelo neoweberiano propuesto por Robert Erikson y John Goldthorpe (1992), el esquema neomarxista de Erik $\mathrm{O}$. Wright ha sido un modelo teóricamente fundamentado de amplio uso en investigaciones empíricas sobre estructura de clases (Bergman y Joye, 2001; Crompton, 1993; Leiulfsrud, Bison y Jensberg, 2005; Li y Singelmann, 1999). En Chile, fue aplicado en el último tiempo para examinar el efecto conjunto de la clase y el género sobre la calidad del empleo (Aguilar y otros, 2016).

Según Wright (1997, págs. 17-26), la posición de clase se deriva del control desigual de los activos productivos, que en la sociedad capitalista contemporánea corresponden a tres principales. El primero de ellos son los medios de producción, cuya posesión desigual genera la diferencia entre clases propietarias y no propietarias (asalariadas). El segundo y tercer activo productivo cuya propiedad es dispar son las calificaciones y los bienes de organización (expresados respectivamente en la posesión de conocimiento experto y la ocupación de cargos investidos de autoridad en las relaciones de producción). La posesión desigual de calificaciones y bienes de autoridad es el mecanismo fundamental que genera distinciones de clase entre los asalariados, por ejemplo, entre trabajadores no calificados y expertos o entre gerentes o supervisores y trabajadores sin autoridad.

En el esquema de Wright, el control desigual de estos tres activos productivos determina la posición de los individuos en las relaciones de explotación. Así, mientras los propietarios de medios de producción ocupan la posición de explotadores en la medida en que contraten fuerza de trabajo ajena, quienes no son propietarios de estos medios ocupan la posición de explotados al vender su fuerza de trabajo. En este contexto, las posiciones de clase media quedan definidas como posiciones que se encuentran en una situación contradictoria de clase (Wright, 1985), ya que si bien son explotadas en su calidad de asalariadas, son explotadoras (o comparativamente menos explotadas) 
pues suponen el control de los activos productivos "calificaciones" y "autoridad". De este modo, un gerente o una profesional serían parte de la clase media y, según este esquema, la expresión de una posición contradictoria de clase. Si bien los gerentes y los profesionales venden su fuerza de trabajo, están dotados al mismo tiempo de altos niveles de calificaciones o autoridad, que los hacen tener una posición privilegiada en relación con los trabajadores no calificados y sin autoridad.

Si se aplica la tesis de la mesocratización a este modelo de análisis, cabría esperar que las posiciones contradictorias de clase - posiciones de clase media dotadas de calificación y autoridadpresentaran un crecimiento sostenido a través del tiempo y que las de clase trabajadora disminuyeran de modo inversamente proporcional. Esta es la principal hipótesis que se pretende contrastar en el análisis empírico detallado a continuación.

\section{Variables, datos y técnica de análisis}

\section{Variables}

Las dos variables principales de este trabajo son la clase social y el sector económico. La variable "clase social" fue elaborada a partir del esquema de clases de Erik O. Wright (1997) pero, considerando los objetivos de este trabajo, se diseñó una versión ligeramente modificada del modelo de 12 clases sociales propuesto por este autor ${ }^{2}$. Específicamente, la categoría de "pequeña burguesía" (autoempleados que no contratan fuerza de trabajo ajena) se dividió entre la pequeña burguesía propiamente tal y los autoempleados informales, con el fin de representar de manera más realista la situación del mercado laboral chileno. De esta forma, las personas propietarias de medios de producción fueron separadas en cuatro posiciones de clase: capitalistas, pequeños empresarios, pequeños burgueses y autoempleados informales.

La población asalariada se analizó sobre la base de cuatro categorías de clase: gerentes, supervisores, expertos y trabajadores (calificados y no calificados). Se decidió utilizar estas cuatro categorías a fin de hacer comparables los resultados de esta investigación con los de otras similares llevadas a cabo conforme a este mismo esquema de clases (Wright, 1997; Wright y Martin, 1987). La homogeneización de estas categorías de clase asalariadas es especialmente importante para este trabajo debido a lo siguiente. Diversas investigaciones en las que se afirma la tesis de la mesocratización tienden a enfatizar que ella se expresa en el crecimiento de posiciones de trabajo altamente calificado, bajo modalidades asalariadas e insertas en el sector de servicios privados (Orellana, 2011, págs. 80 y 81; Ruiz y Boccardo, 2015, pág. 64). Por esta razón, la mayoría de los análisis presentados más adelante se enfocaron en las posiciones de clases asalariadas (gerentes, supervisores, expertos y trabajadores).

En el cuadro 1 se muestran los criterios principales en función de los cuales se elaboraron las ocho categorías de clase. Según se observa, dentro de las clases propietarias se distinguió entre capitalistas, pequeños empresarios, pequeños burgueses (autoempleados que realizan actividades que requieren niveles medios y altos de calificación y pertenecen a los grupos 1 a 4 de la Clasificación Internacional Uniforme de Ocupaciones de 1988 (ClUO-1988)) y autoempleados informales (que trabajan en ocupaciones ubicadas entre los grupos 5 y 9 de la ClUO-1988) ${ }^{3}$. Por su parte, dentro de la población asalariada se distinguió a los encuestados según su nivel de calificación y según lo que Wright (1997, págs. 20-22) define como "bienes de organización" o autoridad.

\footnotetext{
2 Véanse los detalles sobre los criterios que se usaron para la construcción de este esquema de clases en Wright (1997, págs. 74-90).

3 Si bien existen muchas definiciones de "trabajo" y "sector informal" (Portes y Haller, 2004), los datos disponibles solo permitieron usar los criterios generales de clasificación propuestos por el PREALC (1978).
} 
Cuadro 1

Operacionalización de las categorías de clase

\begin{tabular}{|c|c|c|c|c|c|}
\hline & $\begin{array}{l}\text { Es propietario } \\
\text { de medios de } \\
\text { producción }\end{array}$ & $\begin{array}{l}\text { Emplea mano } \\
\text { de obra }\end{array}$ & $\begin{array}{c}\text { Tiene capacidad } \\
\text { de decisión sobre } \\
\text { la administración } \\
\text { y organización } \\
\text { de la empresa }\end{array}$ & $\begin{array}{l}\text { Supervisa el } \\
\text { trabajo de otros }\end{array}$ & $\begin{array}{l}\text { El empleo requiere } \\
\text { la posesión de } \\
\text { calificaciones } \\
\text { educativas de } \\
\text { alto nivel }\end{array}$ \\
\hline 1. Capitalistas & Sí & $\begin{array}{c}\text { Sí } \\
\text { (más de } 10 \text { personas) }\end{array}$ & $-^{c}$ & - & - \\
\hline 2. Pequeños empresarios & Sí & $\begin{array}{c}\text { Sí } \\
\text { (entre } 2 \text { y } 9 \text { personas) }\end{array}$ & - & 一 & - \\
\hline 3. Pequeña burguesía & Sí & No & - & - & - \\
\hline $\begin{array}{l}\text { 4. Autoempleados } \\
\text { informales }\end{array}$ & $\begin{array}{c}\text { Sí } \\
\text { (pero posee } \\
\text { bajos niveles de } \\
\text { calificación) }\end{array}$ & No & - & 一 & - \\
\hline 5. Gerentes & No & No & Sí & 一 & 一 \\
\hline 6. Supervisores & No & No & No & Sí & - \\
\hline 7. Expertos & No & No & No & No & Sí \\
\hline 8. Trabajadores & No & No & No & No & No \\
\hline
\end{tabular}

Fuente: Elaboración propia, sobre la base de E. O. Wright, Class Counts: Comparative Studies in Class Analysis, Cambridge, Cambridge University Press, 1997; y E. O. Wright y B. Martin, "The transformation of the American class structure, 1960-1980", American Journal of Sociology, vol. 93, № 1, Chicago, The University of Chicago Press, 1987.

a Se refiere a la capacidad para contratar o despedir trabajadores, cambiar los bienes o servicios que produce la empresa, cambiar la forma de organizar el trabajo e incidir sobre el presupuesto.

b Por ejemplo, títulos profesionales.

c El guion indica que el criterio no es aplicable para clasificar individuos en esa categoría.

El sector económico fue analizado a partir de la Clasificación Industrial Internacional Uniforme (CIIU). Debido a que las bases utilizadas tenían diferentes versiones de esta clasificación, se decidió armonizar los datos según las 22 categorías presentes en la revisión 3.1 de la CIIU (los problemas de comparabilidad entre los datos no permitieron generar una clasificación más refinada). En algunos análisis más específicos, que se presentan en la sección de resultados, se trabajó con versiones agregadas de los sectores económicos.

\section{Datos}

Los datos usados en este artículo provienen de dos fuentes. La primera de ellas corresponde a la Encuesta de Caracterización Socioeconómica Nacional (CASEN), que es una encuesta de hogares ampliamente utilizada en Chile pues sus marcos muestrales y la cantidad de casos son apropiados para hacer estimaciones representativas a nivel nacional. Además, posee información adecuada (aunque no suficiente) para estimar la cantidad de personas empleadas en diversas posiciones de clase. Ella permite, en efecto, estimar correctamente el número de personas que forman las clases propietarias de medios de producción (empresarios y autoempleados).

El problema surge, sin embargo, en el momento de clasificar a los asalariados. La encuesta CASEN solo cuenta con la variable tradicional derivada de la Clasificación Internacional Uniforme de Ocupaciones (ClUO-1988), sin incluir información que permita distinguir, por ejemplo, a un trabajador sin autoridad de un supervisor o un gerente (es decir, un empleado o empleada de alto nivel, con capacidades administrativas que vayan más allá de la simple supervisión del trabajo de otros). Dado que el objetivo central de este trabajo es testear la tesis de la mesocratización desde una perspectiva de clases teóricamente fundamentada, esto no es un problema menor. Para resolverlo, se decidió clasificar los casos de la encuesta CASEN a partir de información obtenida de la Encuesta Nacional de Empleo, Trabajo, Salud y Calidad de Vida de los Trabajadores y Trabajadoras en Chile (ENETS), que es la segunda fuente de datos de este estudio. La ENETS es una encuesta que fue aplicada entre 
septiembre de 2009 y octubre de 2010 por el Ministerio de Salud, el Ministerio del Trabajo y Previsión Social y el Instituto de Seguridad Laboral de Chile y que es representativa a nivel nacional (15 años o más, $n=9.503$ ). A diferencia de la encuesta CASEN, la ENETS sí permite construir esquemas de clase teóricamente fundamentados, ya que contiene información suficiente para operacionalizar la dimensión de autoridad planteada en el esquema de Wright.

En la sección siguiente se explica en qué consistió la clasificación de los casos de la encuesta CASEN sobre la base de los datos de la ENETS, proceso que permitió la estimación del tamaño de las clases asalariadas para los años 1992, 2003 y 2013. Si bien dicha estimación puede estar sujeta a potenciales problemas asociados a la distancia temporal entre la ENETS y las encuestas CASEN (problemas de los que se habla en la sección siguiente), se decidió trabajar con la ENETS de todas formas ya que ella es, hasta el día de hoy, la única encuesta que permite aplicar el esquema de Wright al caso chileno.

\section{Estimación de las posiciones de clase asalariadas para 1992, 2003 y 2013}

El método de estimación de la estructura de clases utilizado en el presente trabajo fue desarrollado en investigaciones previas sobre transformaciones de esta estructura (Wright, 1997; Wright y Martin, 1987; Wright y Singelmann, 1982). Como se señaló, se usó este método solo para estimar el tamaño de las posiciones de clase asalariadas - las cifras de las clases propietarias se calcularon directamente a partir de la encuesta CASEN-, siguiendo todas las recomendaciones planteadas en dichas investigaciones anteriores (Wright y Martin, 1987, págs. 25-28; Wright y Singelmann, 1982, págs. 192 y 193). La estimación de los casos se llevó a cabo en tres etapas. Primero, a partir de datos de la ENETS se construyó un cuadro con información sobre clase, ocupación y rama de la economía, que permitió apreciar la distribución de clases de cada ocupación dentro de cada rama de la economía. El cuadro presentó, por tanto, la distribución de las 4 clases asalariadas dentro de los 9 grupos ocupacionales (según la ClUO-1988 a un dígito) para cada una de las 22 ramas de la economía. Luego de esto, con los datos de la encuesta CASEN se construyeron cuadros de ocupación y rama económica (es decir, que permitieran distinguir el total de personas en cada ocupación dentro de cada rama) para 1992, 2003 y 2013. Finalmente, se utilizaron los porcentajes del cuadro de clase, ocupación y rama obtenido de la ENETS para estimar la distribución de clases dentro de las celdas de los cuadros de ocupación y rama de la economía elaborados sobre la base de la encuesta CASEN. Por ejemplo, si la ENETS indicó que el $20 \%$ de los trabajadores de oficina (según la variable "ocupación") que estaban empleados en el área de servicios financieros y seguros (según la variable "rama económica") correspondía a supervisores (según la variable "clase social"), entonces el 20\% de los miembros de dicha ocupación en esa rama económica según la encuesta CASEN fueron definidos como supervisores. Este proceso de imputación permitió calcular el total de personas pertenecientes a cada posición de clase asalariada para 1992, 2003 y 2013 (los errores en la codificación de la ocupación de la versión pública de la encuesta CASEN de 1990 impidieron analizar dicho año).

Esta forma de estimación del tamaño de las clases supone que su distribución dentro de cada ocupación y sector económico permanece constante (Wright y Martin, 1987; Wright y Singelmann, 1982, pág. 193). Este supuesto puede ser errado en algunas circunstancias - por ejemplo, si ocurriesen fenómenos de proletarización o mesocratización dentro de cada ocupación-. Si fuera así, es probable que esta forma de estimación no sería la más apropiada para estudiar la distribución de la población en la estructura de clases. A pesar de esto, las investigaciones en que se ha utilizado esta forma de imputación han mostrado que, más allá de estas posibles falencias, la técnica es adecuada en aquellos casos en que el foco está puesto en las transformaciones de la estructura de clases a lo largo de los años antes que en el estudio de la distribución absoluta de la fuerza de trabajo en cada clase. 
Esas investigaciones también han sugerido que los potenciales sesgos asociados a un procedimiento como este no deberían afectar el análisis de los cambios de la estructura en la medida en que ellos se mantengan constantes a través del tiempo, es decir, siempre que se use la misma forma de estimación en todos los períodos estudiados (Wright y Martin, 1987, págs. 10-11)4. Por eso, más allá de sus potenciales limitaciones, esta técnica de imputación resultó muy útil para analizar los cambios de la estructura de clases a partir del marco de análisis neomarxista de Wright y con bases de datos que aseguran tanto la comparabilidad como la representatividad de los datos a nivel nacional ${ }^{5}$.

\section{Técnica de análisis}

En este artículo se examinó la tesis de la mesocratización basándose en la técnica del análisis de la porción de cambio, que ha sido ampliamente utilizada en los análisis empíricos sobre transformaciones de la estructura de clases (Gubbay, 2000; Marshall y Rose, 1988; Wright y Martin, 1987; Wright y Singelmann, 1982) y es apropiada para los objetivos de este trabajo. Además, este método permite dividir los cambios globales que ocurren en la estructura de clases en un período de tiempo dado, distinguiendo entre los cambios asociados a las transformaciones de la composición de clases dentro de cada sector económico (llamados "efecto del cambio en la composición de clases") y los cambios derivados de la transformación de las industrias o sectores económicos en sí mismos (llamados "efecto del cambio industrial"). Junto con lo anterior, esta técnica permite diferenciar una tercera causa de transformación - llamada "efecto de interacción" - la cual es un componente residual que indica el efecto combinado de los cambios en el tamaño de los sectores económicos y la composición de clases dentro de cada uno de ellos.

Esta técnica se basa en la construcción de cuadros de frecuencias contrafactuales para la distribución de las clases en cada sector económico. Al construir los cuadros, se buscó analizar las tres fuentes de cambio antes mencionadas en los períodos de 1992 a 2003 y de 2003 a 2013.

Con el objeto de examinar el efecto del cambio en la composición de clases dentro de las ramas o sectores económicos se elaboró un cuadro de datos contrafactuales que se muestra cuántas personas de determinada clase social (como la clase trabajadora) habría habido en un año (por ejemplo, 2003) - sin considerar el crecimiento total de la fuerza de trabajo - , si el tamaño de los sectores económicos no hubiera cambiado en relación con 1992, pero la distribución de clases dentro de cada sector sí lo hubiera hecho (como se observa en 2003). Este tipo de efecto revela la manera en que una clase crece o se contrae en términos absolutos, independientemente de los cambios que pudiesen existir en los sectores económicos. De este modo, la mesocratización de la estructura de clases se debería expresar en un aumento del número de individuos ubicados en posiciones de clase media dentro de cada sector económico (o en la mayoría de ellos), aun cuando los sectores con un mayor contingente de personas de clase trabajadora (por ejemplo, la agricultura) hayan crecido más rápidamente que aquellos con un mayor número de personas de clase media (como el área de los servicios financieros).

El efecto de la transformación de los sectores o ramas económicas se analizó mediante un cuadro de datos contrafactuales que señala cuántas personas de una clase social cualquiera habría habido en un año determinado (por ejemplo, 2003) - sin considerar el crecimiento de la fuerza de

\footnotetext{
4 Se pueden encontrar más detalles sobre los posibles sesgos asociados a esta técnica de estimación en Wright y Martin (1987, págs. 25-28) y Wright y Singelmann (1982, págs. 207-208).

5 Otro posible sesgo se relaciona con el nivel de agregación de las variables. Los datos usados en este trabajo solo permitieron una desagregación en 22 sectores económicos (y no 37 como en las investigaciones anteriores en que se usó este método de imputación). A fin de testear las posibles falencias asociadas a este problema, el autor estimó el tamaño de las clases con diferentes versiones de la variable "rama económica" para los años en que los datos permitieron hacerlo (2003 y 2013). Estos cálculos solo indicaron variaciones menores en el tamaño de cada clase (que, en relación con la estructura de clases total que acá se presenta, no fueron mayores del 1\%). Más importante aún, el análisis de dichos datos reveló que la pauta de cambio de la estructura de clases - o sea, el crecimiento o disminución del tamaño de las clases - fue exactamente la misma que la expuesta en este trabajo.
} 
trabajo - , si la composición de clases dentro de cada rama hubiera sido la misma que la del año de análisis anterior (1992), pero el tamaño de cada sector económico - es decir, la cantidad de personas empleadas en ellos - hubiera cambiado (como se observa en 2003). En términos conceptuales, este tipo de efecto muestra el modo en que cambia la estructura de clases como resultado del crecimiento o contracción de ciertos sectores económicos. Así, el crecimiento de los sectores de servicios educacionales y sociales podría ser visto como una fuerza importante detrás de la mesocratización de la estructura de clases, en la medida en que esos ámbitos cuentan con grandes contingentes de fuerza de trabajo altamente calificada. Si dichos sectores crecen más rápidamente que otros que tienen una fuerza de trabajo no calificada numerosa (por ejemplo, la agricultura), se debería observar entonces un crecimiento absoluto y relativo de las posiciones de clase media en la estructura de clases total. Este cambio es visto, desde la perspectiva de esta técnica de análisis, como un efecto del cambio de los sectores o ramas económicas.

Por último, el efecto de interacción es un elemento residual que representa los cambios de la estructura de clases que se derivan del movimiento de personas desde una clase dentro de un sector económico hasta otra en un sector económico distinto. En ese sentido, muchos analistas de la estructura de clases latinoamericana han afirmado que la transformación neoliberal de las décadas de 1980 y 1990 implicó un proceso de desindustrialización y terciarización, junto con un incremento de la pequeña burguesía (especialmente la de tipo informal), resultante del "emprendimiento forzado" al cual estuvieron sometidos muchos antiguos asalariados (Klein y Tokman, 2000; Portes y Hoffman, 2003; Weller, 2004). De acuerdo con la técnica que se presenta en este artículo, el efecto de interacción estaría expresado en la contracción de las posiciones de clase trabajadora de "cuello azul" y del sector industrial que las generaba, así como en el incremento del sector terciario y de las actividades independientes. En otras palabras, dicho efecto sería entendido como el resultado conjunto del cambio en la composición de clases dentro de las industrias (dado en este caso por la disminución de trabajos asalariados obreros y el aumento del trabajo independiente) y la transformación global de los sectores económicos (dada por la contracción del sector industrial y la expansión del sector de servicios).

En el anexo se explican brevemente los procedimientos aplicados para confeccionar estos cuadros de datos contrafactuales.

\section{Resultados}

El cuadro 2 muestra los cambios principales registrados en el tamaño de los sectores económicos, agrupados en 22 categorías, al comparar los años 1992, 2003 y 2013. Los datos confirman las tendencias señaladas en diversas investigaciones anteriores, a saber: que la estructura económica de Chile ha experimentado una reducción sostenida del empleo en el sector primario (especialmente en las actividades de agricultura, caza y silvicultura), la contracción de algunas actividades industriales (por ejemplo, aquellas relacionadas con los textiles y el cuero) y un aumento del empleo en el sector de servicios (Gayo Méndez y Teitelboim, 2016; León y Martínez, 2007). Estos hechos darían la razón a la tesis de la mesocratización, según la cual las actividades de intermediación financiera, inmobiliarias y empresariales tienden a requerir niveles de calificación elevados. Por lo tanto, su crecimiento debería expresarse en un incremento sostenido de posiciones de clase media asalariada y en la consolidación de una estructura más mesocratizada (Ruiz y Boccardo, 2015, pág. 112).

La consolidación de una estructura mesocratizada se relativiza, sin embargo, al analizar los datos del cuadro 3, que contiene los cambios observados en la estructura de clases de Chile si se consideran los años 1992, 2003 y 2013. Solo con fines comparativos este cuadro también incluye datos (únicamente los porcentajes) de los Estados Unidos entre 1960 y 1980, calculados por Wright y Martin (1987) con un esquema de la estructura de clases básicamente igual al que se utilizó en este estudio. 


\section{Cuadro 2}

Chile: total de población ocupada según sector económico, 1992-2013

(En número de personas y porcentajes)

\begin{tabular}{lrrrrrr}
\hline & $\begin{array}{c}1992 \\
\text { Número de } \\
\text { personas }\end{array}$ & Porcentajes & $\begin{array}{c}\text { 2003 } \\
\text { Número de } \\
\text { personas }\end{array}$ & Porcentajes & $\begin{array}{c}\text { Número de } \\
\text { personas }\end{array}$ & Porcentajes \\
\hline 1. Agricultura, caza y silvicultura & 677907 & 14,3 & 688707 & 11,9 & 610668 & 8,6 \\
\hline 2. Pesca & 66621 & 1,4 & 80457 & 1,4 & 51792 & 0,7 \\
\hline 3. Minas y canteras & 104665 & 2,2 & 87497 & 1,5 & 200190 & 2,8 \\
\hline 4. Fabricación de alimentos, bebidas y tabaco & 164105 & 3,5 & 209540 & 3,6 & 272644 & 3,8 \\
\hline 5. Fabricación de textiles y cuero & 237681 & 5,0 & 127450 & 2,2 & 91067 & 1,3 \\
\hline 6. Fabricación de madera, papel y otros & 160458 & 3,4 & 179689 & 3,1 & 181574 & 2,5 \\
\hline 7. Fabricación de petróleo y productos químicos & 52391 & 1,1 & 62155 & 1,1 & 41334 & 0,6 \\
\hline 8. Fabricación de plástico y minerales no metálicos & 55292 & 1,2 & 42639 & 0,7 & 44008 & 0,6 \\
\hline 9. Fabricación de metales & 92204 & 1,9 & 109625 & 1,9 & 106699 & 1,5 \\
\hline 10. Fabricación y reparación de equipamiento & 49370 & 1,0 & 55286 & 1,0 & 65517 & 0,9 \\
\hline 11. Suministro de electricidad, gas y agua & 37132 & 0,8 & 33949 & 0,6 & 40261 & 0,6 \\
\hline 12. Construcción & 431564 & 9,1 & 508957 & 8,8 & 680510 & 9,5 \\
\hline 13. Comercio (al por mayor y al detalle) & 736562 & 15,5 & 966941 & 16,7 & 1174812 & 16,5 \\
\hline 14. Hoteles y restaurantes & 111914 & 2,4 & 174016 & 3,0 & 313968 & 4,4 \\
\hline 15. Transportes, almacenamiento y comunicaciones & 339412 & 7,2 & 464319 & 8,0 & 562806 & 7,9 \\
\hline 16. Finanzas, seguros y actividades inmobiliarias & 95606 & 2,0 & 142020 & 2,4 & 174508 & 2,4 \\
\hline 17. Servicios a empresas & 126288 & 2,7 & 276861 & 4,8 & 431162 & 6,0 \\
\hline 18. Administración pública y defensa & 104206 & 2,2 & 156074 & 2,7 & 260790 & 3,7 \\
\hline 19. Enseñanza & 269574 & 5,7 & 402411 & 6,9 & 554876 & 7,8 \\
\hline 20. Asistencia social y salud & 168871 & 3,6 & 243170 & 4,2 & 389898 & 5,5 \\
\hline 21. Servicios comunitarios y personales & 609600 & 12,9 & 710352 & 12,2 & 757653 & 10,6 \\
\hline 22. Servicios recreacionales & 52511 & 1,1 & 79344 & 1,4 & 120872 & 1,7 \\
\hline Total & 4743934 & 100 & 5801459 & 100 & 7127609 & 100 \\
\hline
\end{tabular}

Fuente: Elaboración propia, sobre la base de datos de la Encuesta de Caracterización Socioeconómica Nacional (CASEN).

\section{Cuadro 3}

Cambios en la estructura de clases en Chile (1992-2013) y los Estados Unidos (1960-1980)

(En número de personas y porcentajes)

\begin{tabular}{|c|c|c|c|c|c|c|c|c|c|}
\hline \multirow{3}{*}{ Clase social } & \multicolumn{6}{|c|}{ Chile } & \multicolumn{3}{|c|}{ Estados Unidos $^{\mathrm{a}}$} \\
\hline & \multicolumn{2}{|c|}{1992} & \multicolumn{2}{|c|}{2003} & \multicolumn{2}{|c|}{2013} & 1960 & 1970 & 1980 \\
\hline & $\begin{array}{l}\text { Número } \\
\text { de } \\
\text { personas }\end{array}$ & Porcentajes & $\begin{array}{l}\text { Número de } \\
\text { personas }\end{array}$ & Porcentajes & $\begin{array}{l}\text { Número de } \\
\text { personas }\end{array}$ & Porcentajes & & Porcentajes & \\
\hline \multicolumn{10}{|l|}{ Propietarios } \\
\hline 1. Capitalistas & 41631 & 0,9 & 50705 & 0,9 & 29106 & 0,4 & 8,0 & 5,5 & 5,0 \\
\hline 2. Pequeños empresarios & 126337 & 2,7 & 176896 & 3,0 & 84840 & 1,2 & & & \\
\hline 3. Pequeña burguesía & 166874 & 3,5 & 302064 & 5,2 & 372109 & 5,2 & 5,8 & 4,4 & 4,3 \\
\hline 4. Autoempleados informales & 877442 & 18,5 & 903190 & 15,6 & 1054839 & 14,8 & & & \\
\hline \multicolumn{10}{|l|}{ Asalariados } \\
\hline 5. Gerentes & 66446 & 1,4 & 81276 & 1,4 & 104560 & 1,5 & 14,8 & 16,3 & 18,4 \\
\hline 6. Supervisores & 557486 & 11,8 & 708075 & 12,2 & 947584 & 13,3 & 11,5 & 12,4 & 13,2 \\
\hline 7. Expertos & 130984 & 2,8 & 192922 & 3,3 & 271451 & 3,8 & 5,6 & 7,4 & 8,6 \\
\hline 8. Clase trabajadora & 2776735 & 58,5 & 3386332 & 58,4 & 4263120 & 59,8 & 54,3 & 54,1 & 50,5 \\
\hline Total & 4743934 & 100 & 5801459 & 100 & 7127609 & 100 & 100 & 100 & 100 \\
\hline
\end{tabular}

Fuente: Elaboración propia, sobre la base de datos de la Encuesta Nacional de Empleo, Trabajo, Salud y Calidad de Vida de los Trabajadores y Trabajadoras de Chile (ENETS) (2009-2010) y la Encuesta de Caracterización Socioeconómica Nacional (CASEN) (1992-2013) y E. O. Wright y B. Martin, "The transformation of the American class structure, 1960-1980", American Journal of Sociology, vol. 93, № 1, Chicago, The University of Chicago Press, 1987.

a En los Estados Unidos las clases "capitalistas" y "pequeños empresarios" se agruparon en una gran categoría. De modo similar, la categoría "pequeña burguesía" incluye lo que acá se define como "pequeña burguesía" y "autoempleados informales". 
Es importante destacar dos fenómenos. Primero, en los tres años, y de modo casi invariable, la mayoría de los chilenos (alrededor del 59\%) se ubican en una posición de clase trabajadora. Esto pone en duda el carácter de clase media de la estructura de clases chilena, especialmente si se considera la gran cantidad de autoempleados informales (quienes comúnmente son entendidos en la literatura latinoamericana como parte integral de los sectores populares junto con la clase trabajadora). A pesar de su disminución a través de los años, en 2013 los autoempleados informales eran casi el 15\% de los ocupados. Así, en ese año casi el $75 \%$ de la población pertenecía a la parte más baja de la estructura de clases (autoempleados informales y clase trabajadora).

El segundo fenómeno digno de mención es que las posiciones de clase media asalariada - gerentes, supervisores y expertos - sí aumentaron entre 1992 y 2013. No obstante, su incremento fue más bien moderado (entre 1992 y 2013 ninguna de esas categorías creció más de 1,5 puntos porcentuales) y además estuvo acompañado, en el período de 2003 a 2013, de un crecimiento similar de la clase trabajadora (que aumentó 1,4 puntos porcentuales). De este modo, los datos indican que en el año en que la estructura de clases estuvo más mesocratizada (2013), las posiciones de clase media asalariada representaron solo el 18,6\% del total de ocupados. Esto no deja de ser llamativo si los datos se comparan con aquellos de los Estados Unidos, que muestran que en 1980 la suma de gerentes, supervisores y expertos representaba poco más de un $40 \%$ del total de los ocupados. Asimismo, es posible observar que en ese país la clase de los gerentes ha representado siempre una porción significativa de la fuerza de trabajo, pasando de un 14,8\% en 1960 a más del 18\% en 1980 . En Chile, por el contrario, los gerentes no sobrepasan el 1,5\% en cualquiera de los años considerados. Algo similar ocurre con la categoría de expertos. Si bien estos aumentaron de un 2,8\% en 1992 a un 3,8\% en 2013 -que puede ser el resultado de la expansión de la educación superior durante las últimas décadas (Espinoza, Barozet y Méndez, 2013; Ruiz y Boccardo, 2015)-, dicho aumento es más bien moderado en comparación con el de los Estados Unidos y no alcanza a revertir el carácter débilmente mesocrático de la estructura de clases chilena.

Habiendo referido estos cambios globales de la estructura de clases, conviene ahora describir de modo más específico esos fenómenos. El cuadro 4 muestra la descomposición de los cambios de la estructura de clases obtenidos del análisis de la porción de cambio para los períodos de 1992 a 2003 y de 2003 a 2013. La columna I del cuadro indica el cambio total observado en cada clase (es decir, cuánto aumentó o disminuyó en cada período), mientras que la columna II muestra el cambio esperado o, lo que es lo mismo, cuánto debería haber crecido cada clase si hubiese aumentado en la misma proporción en que creció el total de la población ocupada. La columna III representa el cambio neto de cada clase social - o sea, el que se calcula controlando por el crecimiento de la fuerza de trabajo -, mientras que las columnas de la IV a la VI muestran la fuente o el origen de dicho cambio (por eso la suma de estos efectos es igual al cambio neto de cada clase). En otras palabras, las columnas entre la IV y la VI representan los cambios de la estructura de clases como efecto de: i) la transformación de los sectores económicos (columna IV); ii) los cambios de la composición de clases dentro de cada sector (columna V), y iii) el efecto conjunto o interacción de ambos factores (columna VI) ${ }^{6}$. Las columnas de la VII a la X presentan la misma información que las columnas de la III a la VI, pero como porcentaje del número de personas en cada clase al inicio de los períodos analizados (1992 para el primer período y 2003 para el segundo).

\footnotetext{
${ }^{6}$ Como se señaló en la sección metodológica, en el anexo se presenta una breve explicación de los cuadros de datos contrafactuales a partir de los cuales se obtuvo la información del cuadro 4.
} 


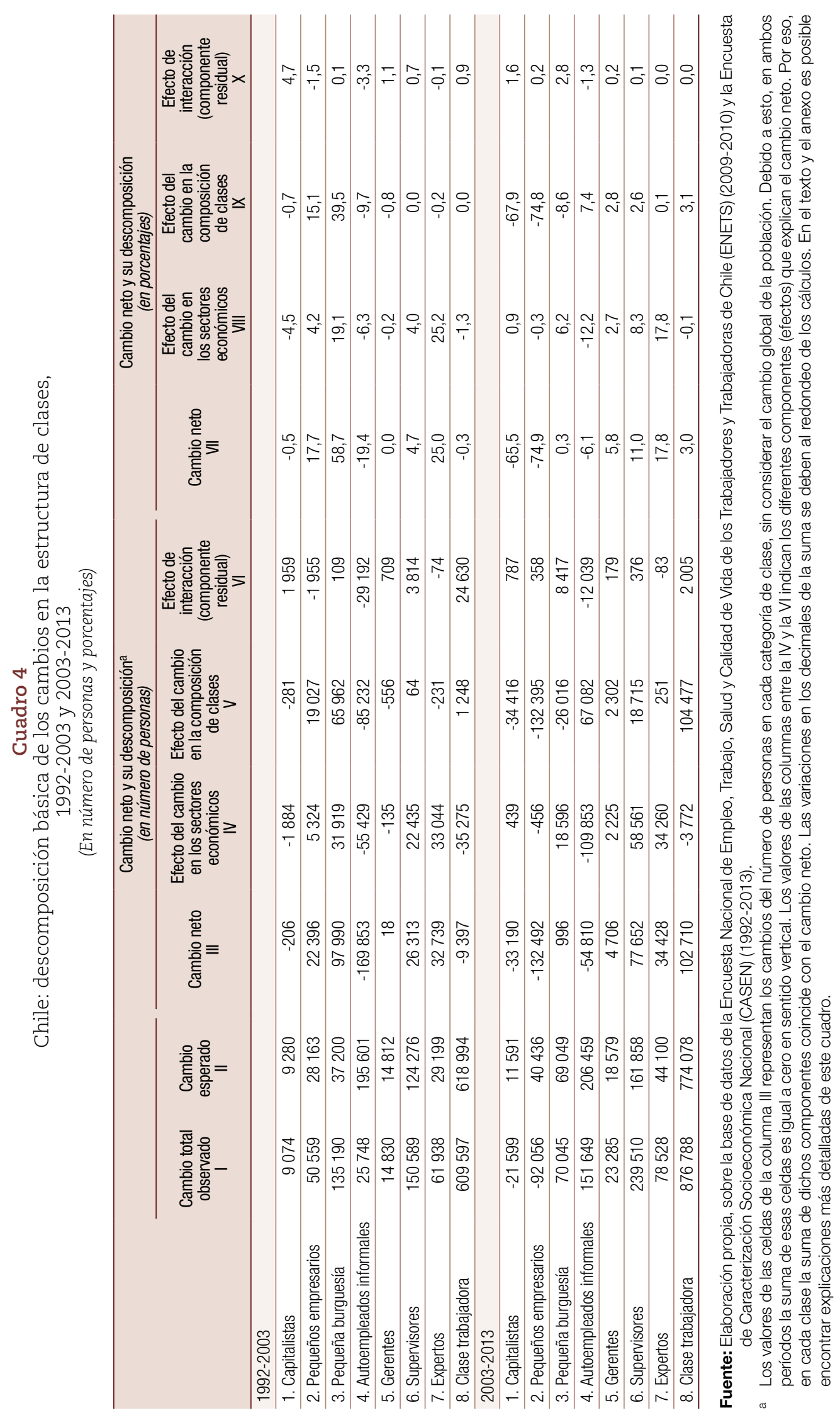


Al examinar las columnas III y VII en el tramo de 1992 a 2003 se puede observar que, sin considerar el crecimiento de la fuerza de trabajo ocupada, la clase de los expertos creció en 32.739 personas (lo que equivale a un incremento del $25 \%$ ), en tanto que la clase trabajadora tuvo una disminución neta de 9.397 personas, equivalente a un cambio neto del -0,3\%. En el caso de los expertos, la descomposición del cambio neto indica que su crecimiento obedece a una transformación de los sectores económicos. Dicha transformación se tradujo, en efecto, en un aumento neto de 33.044 personas (columna IV). Esto equivalió a un incremento neto del 25,2\% (columna VII), que se vio compensado por leves reducciones: del 0,2\% como consecuencia del cambio de la composición de clases y el $0,1 \%$ producto del efecto de interacción (columnas VII y VIII).

En el período comprendido entre 2003 y 2013 se advierten tendencias similares a las que exhibe el primer tramo. Cabe resaltar, sin embargo, dos fenómenos. En primer lugar, a diferencia del período de 1992 a 2003, en que los gerentes prácticamente no experimentaron cambios netos, en este segundo lapso se observa que dicha categoría presentó un crecimiento neto del 5,8\% (columna VII). Dicho aumento no fue, sin embargo, demasiado relevante en términos absolutos (según se muestra en la columna III, ese 5,8\% equivale solo a 4.706 personas). El segundo fenómeno que merece ser destacado es el cambio neto positivo de la clase trabajadora, que se expresó en que en 2013 hubo 102.710 más trabajadores que en 2003 (columna III). El gran tamaño de esta clase explica por qué dicho crecimiento neto absoluto (que fue el mayor de los observados con respecto a cualquiera de las clases en cualquiera de los dos períodos) solo significó un incremento porcentual del 3\% (columna VII). La descomposición de ese porcentaje sugiere que gran parte del crecimiento de la clase trabajadora es un efecto del cambio de la composición de clases dentro de los sectores económicos (columna IX).

Es interesante señalar también lo que ocurre en ambos períodos con la pequeña burguesía y los autoempleados informales. En la pequeña burguesía se observa un constante crecimiento que, no obstante, se desacelera notoriamente en el segundo período (entre 1992 y 2003 dicha clase tuvo un crecimiento neto del 58,7\%, en tanto que entre 2003 y 2013 este fue solo de un 0,3\%). Entre los autoempleados informales se observa una tendencia contraria: su disminución se desacelera en el segundo período. De este modo, mientras que entre 1992 y 2003 el cambio neto de esa clase fue del $-19,4 \%$, en el período de 2003 a 2013 este fue del $-6,1 \%$.

Estos resultados relativizan la tesis de la mesocratización, al menos respecto de los dos períodos aquí analizados. Si bien entre 1992 y 2013 se pudo observar un crecimiento neto de las posiciones de clase media asalariada, este fue extremadamente bajo y no alcanzó a producir transformaciones significativas en la estructura de clases. Es más, dicho crecimiento estuvo acompañado entre 2003 y 2013 por un incremento neto de la cantidad de personas empleadas en posiciones de clase trabajadora. Tal incremento fue, de hecho, el mayor en términos absolutos considerando los dos períodos estudiados (véase la columna III del cuadro 4). En suma, los datos indican que la idea de una estructura cada vez más mesocratizada es difícil de sostener desde una perspectiva de clases como la utilizada en este estudio.

Para tener una imagen más acabada de estas tendencias, el cuadro 5 presenta los efectos de los cambios ocurridos en las industrias y la composición de clases (columnas VIII y IX del cuadro 4), desagregados en cinco grandes sectores económicos ${ }^{7}$. Este cuadro es útil como complemento de la información ya descrita en el cuadro 4. Por ejemplo, al analizar este último se advirtió que el crecimiento neto de los expertos entre 1992 y 2003 fue mayoritariamente un efecto del cambio en los sectores económicos (según se expuso, dicho efecto se expresó en un cambio neto positivo del $25,2 \%$ ). Los datos del cuadro 5 sugieren que la mayor parte de ese aumento asociado a la

\footnotetext{
7 Estos sectores económicos resultaron del agrupamiento de las 22 ramas presentadas en el cuadro 2. La agregación se hizo de la siguiente manera: sector extractivo (actividades 1 a 3); sector manufacturero, de la construcción y de suministros (4 a 12); comercio, hoteles y restaurantes, transporte y comunicaciones (13 a 15); seguros, servicios financieros y servicios a empresas (16 y 17), y servicios públicos, sociales, comunitarios y personales (18 a 22).
} 
transformación de los sectores económicos se explica por el crecimiento de las actividades agrupadas en la categoría "servicios públicos, sociales, comunitarios y personales". La expansión de esas actividades implicó, en efecto, un aumento neto de los expertos del 94,7\%. Una tendencia similar se puede observar en el segundo período analizado. Como ocurrió entre 1992 y 2003, el incremento neto de los expertos entre 2003 y 2013 es consecuencia, en gran medida, del cambio en los sectores económicos y particularmente del crecimiento de las actividades asociadas a servicios públicos, sociales, comunitarios y personales.

\section{Cuadro 5}

Chile: desagregación de los efectos del cambio en los sectores económicos y en la composición de clases según sector económico, 1992-2003 y 2003-2013

(En porcentajes)

\begin{tabular}{|c|c|c|c|c|c|c|}
\hline & $\begin{array}{c}\text { Sector } \\
\text { extractivo }\end{array}$ & $\begin{array}{l}\text { Manufacturas, } \\
\text { suministros y } \\
\text { construcción }\end{array}$ & $\begin{array}{c}\text { Comercio, } \\
\text { hoteles, } \\
\text { transporte y } \\
\text { comunicaciones }\end{array}$ & $\begin{array}{c}\text { Seguros, } \\
\text { y servicios } \\
\text { financieros y } \\
\text { a empresas }\end{array}$ & $\begin{array}{l}\text { Servicios } \\
\text { públicos, sociales, } \\
\text { comunitarios y } \\
\text { personales }\end{array}$ & Total \\
\hline \multicolumn{7}{|l|}{$1992-2003$} \\
\hline \multicolumn{7}{|l|}{ 1. Capitalistas } \\
\hline Cambio en los sectores económicos & 0,6 & 15,2 & 8,3 & $-0,9$ & $-27,8$ & $-4,5$ \\
\hline Cambio en la composición de clases & $-0,5$ & 22,4 & $-2,6$ & $-20,3$ & $-0,7$ & $-0,7$ \\
\hline \multicolumn{7}{|l|}{ 2. Pequeños empresarios } \\
\hline Cambio en los sectores económicos & 1,1 & $-8,0$ & 31,7 & 3,1 & $-23,7$ & 4,2 \\
\hline Cambio en la composición de clases & 0,5 & 11,3 & 16,7 & $-14,8$ & 15,1 & 15,1 \\
\hline \multicolumn{7}{|l|}{ 3. Pequeña burguesía } \\
\hline Cambio en los sectores económicos & $-15,8$ & $-18,2$ & 36,4 & 21,2 & $-4,5$ & 19,1 \\
\hline Cambio en la composición de clases & $-12,6$ & $-10,9$ & 68,4 & $-12,2$ & 39,5 & 39,5 \\
\hline \multicolumn{7}{|l|}{ 4. Autoempleados informales } \\
\hline Cambio en los sectores económicos & 4,5 & $-2,9$ & 13,9 & $-7,7$ & $-14,1$ & $-6,3$ \\
\hline Cambio en la composición de clases & 8,2 & 10,2 & $-3,5$ & $-16,1$ & $-9,7$ & $-9,7$ \\
\hline \multicolumn{7}{|l|}{ 5.Gerentes } \\
\hline Cambio en los sectores económicos & $-3,0$ & 6,4 & $-8,5$ & 5,9 & $-1,1$ & $-0,2$ \\
\hline Cambio en la composición de clases & 0,2 & 10,2 & $-9,4$ & $-3,3$ & $-0,8$ & $-0,8$ \\
\hline \multicolumn{7}{|l|}{ 6. Supervisores } \\
\hline Cambio en los sectores económicos & $-4,9$ & 6,5 & $-5,6$ & 1,3 & 6,6 & 4,0 \\
\hline Cambio en la composición de clases & $-1,5$ & 8,8 & $-6,4$ & 1,1 & 0,0 & 0,0 \\
\hline \multicolumn{7}{|l|}{ 7. Expertos } \\
\hline Cambio en los sectores económicos & $-17,5$ & $-25,1$ & $-29,3$ & 2,5 & 94,7 & 25,2 \\
\hline Cambio en la composición de clases & $-17,2$ & $-25,0$ & $-29,5$ & 72,0 & $-0,2$ & $-0,2$ \\
\hline \multicolumn{7}{|l|}{ 8. Clase trabajadora } \\
\hline Cambio en los sectores económicos & 1,3 & 1,9 & $-5,4$ & 0,5 & 0,5 & $-1,3$ \\
\hline Cambio en la composición de clases & 5,8 & 4,2 & $-6,3$ & $-1,0$ & 0,0 & 0,0 \\
\hline \multicolumn{7}{|l|}{ 2003-2013 } \\
\hline \multicolumn{7}{|l|}{ 1. Capitalistas } \\
\hline Cambio en los sectores económicos & $-3,9$ & 13,9 & 1,4 & 8,6 & $-19,1$ & 0,9 \\
\hline Cambio en la composición de clases & $-6,5$ & $-8,4$ & $-25,4$ & 0,9 & $-28,5$ & $-67,9$ \\
\hline \multicolumn{7}{|l|}{ 2. Pequeños empresarios } \\
\hline Cambio en los sectores económicos & $-4,5$ & $-0,1$ & 15,6 & 6,4 & $-17,7$ & $-0,3$ \\
\hline Cambio en la composición de clases & $-8,8$ & $-13,5$ & $-19,5$ & $-4,6$ & $-28,5$ & $-74,8$ \\
\hline \multicolumn{7}{|l|}{ 3. Pequeña burguesía } \\
\hline Cambio en los sectores económicos & $-12,6$ & $-17,0$ & 40,8 & 12,1 & $-17,1$ & 6,2 \\
\hline Cambio en la composición de clases & $-10,8$ & $-14,5$ & 14,9 & 10,0 & $-8,2$ & $-8,6$ \\
\hline \multicolumn{7}{|l|}{ 4. Autoempleados informales } \\
\hline Cambio en los sectores económicos & 4,2 & 7,0 & 4,5 & $-9,6$ & $-18,2$ & $-12,2$ \\
\hline Cambio en la composición de clases & 8,6 & 10,0 & 12,6 & $-8,8$ & $-14,9$ & 7,4 \\
\hline 5.Gerentes & & & & & & \\
\hline
\end{tabular}


Cuadro 5 (conclusión)

\begin{tabular}{lcccccc}
\hline & $\begin{array}{c}\text { Sector } \\
\text { extractivo }\end{array}$ & $\begin{array}{c}\text { Manufacturas, } \\
\text { suministros y } \\
\text { construcción }\end{array}$ & $\begin{array}{c}\text { Comercio, } \\
\text { hoteles, } \\
\text { transporte y } \\
\text { comunicaciones }\end{array}$ & $\begin{array}{c}\text { Seguros, } \\
\text { y servicios } \\
\text { financieros y } \\
\text { a empresas }\end{array}$ & $\begin{array}{c}\text { Servicios } \\
\text { públicos, sociales, } \\
\text { comunitarios y } \\
\text { personales }\end{array}$ & Total \\
\hline Cambio en los sectores económicos & $-1,7$ & 3,8 & $-5,5$ & 6,4 & $-0,3$ & 2,7 \\
\hline Cambio en la composición de clases & 0,9 & 7,4 & $-6,5$ & 4,3 & $-3,3$ & 2,8 \\
\hline 6. Supervisores & & & & & & \\
\hline Cambio en los sectores económicos & $-2,3$ & 3,1 & $-4,0$ & 1,0 & 10,4 & 8,3 \\
\hline Cambio en la composición de clases & $-1,4$ & 6,2 & $-4,3$ & $-0,6$ & 2,6 & 2,6 \\
\hline 7. Expertos & & & & & & \\
\hline Cambio en los sectores económicos & $-13,9$ & $-24,1$ & $-31,4$ & $-0,2$ & 87,4 & 17,8 \\
\hline Cambio en la composición de clases & $-14,3$ & $-23,9$ & $-31,1$ & $-1,2$ & 70,7 & 0,1 \\
\hline 8. Clase trabajadora & & & & & & $-0,1$ \\
\hline Cambio en los sectores económicos & 1,6 & 0,1 & $-2,9$ & 0,7 & 0,4 & 3,1 \\
\hline Cambio en la composición de clases & 5,9 & 2,6 & $-2,8$ & $-0,9$ & $-1,7$ & \\
\hline
\end{tabular}

Fuente: Elaboración propia, sobre la base de datos de la Encuesta Nacional de Empleo, Trabajo, Salud y Calidad de Vida de los Trabajadores y Trabajadoras de Chile (ENETS) (2009-2010) y la Encuesta de Caracterización Socioeconómica Nacional (CASEN) (1992-2013).

Nota: Los valores de cada celda deben ser interpretados como la contribución de cada sector económico a los componentes del cambio en los sectores económicos y en la composición de clases. El total de cada fila representa, por tanto, los efectos del cambio de los sectores económicos y de la composición de clases del cuadro 4 (columnas VIII y IX).

El cuadro 5 también permite explicar el incremento neto del número de personas empleadas en posiciones de clase trabajadora entre 2003 y 2013. Según se vio con anterioridad, ese cambio neto positivo es básicamente un efecto de los cambios en la distribución de clases dentro de los sectores económicos (que significaron, conforme a la columna IX del cuadro 4, un crecimiento de los trabajadores del 3,1\%). Como se observa en el cuadro 5, la mayor parte de ese aumento neto se debe al crecimiento de la clase trabajadora dentro del sector extractivo, que experimentó, en efecto, un incremento neto de trabajadores del 5,9\%. Esto significa que dentro de ese sector, y más allá de su crecimiento o contracción, existió un proceso de proletarización que se tradujo, en 2013, en que hubo más personas empleadas en posiciones de clase trabajadora. De acuerdo con el cuadro 5, algo similar - pero en menor proporción- ocurrió con el crecimiento de la clase trabajadora en actividades asociadas al sector manufacturero, de suministros y de la construcción.

\section{Conclusiones}

La principal conclusión que se puede obtener de este trabajo es que el argumento central de la tesis de la mesocratización en Chile - a saber, la idea de que el crecimiento del sector de servicios ha traído consigo una estructura social de clase media - es cuestionable, al menos en relación con el período analizado. Es cierto que Chile ha experimentado una reducción constante de la fuerza de trabajo empleada en el sector industrial. También lo es que el crecimiento de algunas actividades de la rama de los servicios afecta positivamente el aumento de la clase media (eso es precisamente lo que se puso de manifiesto en este trabajo cuando se afirmó que el incremento neto de los expertos es un efecto del crecimiento de actividades ligadas a los servicios públicos, sociales, comunitarios y personales). Sin embargo, aunque estas tendencias han sido relevadas correctamente por muchos de quienes sostienen la idea de la mesocratización (León y Martínez, 2007; Ruiz y Boccardo, 2015), lo que es discutible es que estos fenómenos sean lo suficientemente importantes en términos cuantitativos (absolutos y relativos) como para hablar de una estructura de clases cada vez más mesocratizada. Como se advirtió, la estructura de clases de Chile se caracteriza por la gran persistencia de sus características generales. Tales características indican que la sociedad chilena tiene mucho más de 
clase trabajadora que de clase media (según el esquema que se utiliza en este trabajo, mientras la clase trabajadora por sí sola incluye a cerca del $60 \%$ de los ocupados, dicho valor llega casi al $75 \%$ cuando se incluye a los autoempleados informales). En ese sentido, estos resultados son similares a los obtenidos en otras investigaciones en que se ha cuestionado que la terciarización de la economía chilena haya hecho de Chile un país de clase media (Gayo, Méndez y Teitelboim, 2016).

Considerando el ritmo de crecimiento de las posiciones de clase media, así como el incremento de las personas empleadas en posiciones de clase trabajadora observado entre 2003 y 2013, es difícil pensar que en algún momento la clase media llegue a ser un sector numéricamente dominante de la estructura de clases. Esta conclusión podría ser incluso menos optimista si se piensa que ambos períodos analizados deberían haber capturado los resultados positivos de dos décadas caracterizadas por altos niveles de crecimiento económico (salvo en 1999 y 2009, Chile experimentó un aumento anual del producto interno bruto (PIB) que, en promedio, estuvo por sobre el $4 \%$ ). De la misma manera, la comparación con investigaciones similares realizadas en los Estados Unidos a finales de la década de 1980 (Wright y Martin, 1987) pone en evidencia que la asociación entre desindustrialización, emergencia de una sociedad de servicios y crecimiento de la clase media es algo que bien puede aplicarse (bajo ciertas circunstancias) a sociedades capitalistas avanzadas, pero que puede ser insuficiente para entender el caso de Chile.

¿Qué explica, entonces, que la idea de la mesocratización se haya convertido en uno de los conceptos más usados para analizar los cambios recientes de la sociedad chilena? Una posible explicación se refiere a la manera en que se ha definido la noción de clase social en las investigaciones; específicamente al hecho de que se han usado definiciones que reflejan una tendencia a asociar automáticamente el cambio en los sectores económicos - expresado, por ejemplo, en el crecimiento del sector de servicios - con el cambio en la estructura de clases - expresado, supuestamente, en la ampliación de trabajos de clase media no manuales-. Según la estrategia de análisis usada en el presente estudio, dicha asociación automática se traduce en la confusión de dos fuentes de cambio diferentes: una observada en los sectores económicos y la otra en la composición de clases dentro de los sectores económicos. A través de la determinación empírica de ambas fuentes de cambio, así como de la utilización de esquemas de análisis teóricamente fundamentados, en este trabajo se intentó contribuir al análisis de clase mostrando cómo la estructura de clases chilena es más polarizada y resistente al cambio de lo que muchos suponen.

\section{Bibliografía}

Aguilar, O. y otros (2016), "Intersección entre la clase y el género y su efecto sobre la calidad del empleo en Chile", Revista CEPAL, № 120 (LC/G.2694-P), Santiago, Comisión Económica para América Latina y el Caribe (CEPAL).

Barozet, E. y J. Fierro (2011), "Clase media en Chile, 1990-2011: algunas implicancias sociales y políticas", Serie de Estudios, № 4, Santiago, Fundación Konrad Adenauer.

Bell, D. (1973), The Coming of Post-Industrial Society, Nueva York, Basic Books.

Bergman, M. M. y D. Joye (2001), "Comparing Social Stratification Schemas: CAMSIS, CSP-CH, Goldthorpe, ISCO-88, Treiman, and Wright" [en línea] http://forscenter.ch/wp-content/uploads/2013/11/indicateursposition-sociale-en1.pdf.

Bourdieu, P. (1984), Distinction: A Social Critique of the Judgement of Taste, Cambridge, Massachusetts, Harvard University Press.

Braverman, H. (1998), Labor and Monopoly Capitalism: the Degradation of Work in the Twentieth Century, Nueva York, Monthly Review Press.

Castellani, F. y G. Parent (2011), "Being 'middle-class' in Latin America", Documento de Trabajo, № 305, París, Organización de Cooperación y Desarrollo Económicos (OCDE).

Crompton, R. (1993), Class and Stratification. An Introduction to Current Debates, Cambridge, Polity Press. 
Crompton, R. y G. A. Jones (1984), White-Collar Proletariat: Deskilling and Gender in Clerical Work, Londres, MacMillan.

Dahrendorf, R. (1959), Class and Class Conflict in Industrial Society, Stanford, Stanford University Press.

Do Valle Silva, N. (2007), "Cambios sociales y estratificación en el Brasil contemporáneo (1945-1999)", Estratificación y movilidad social en América Latina. Transformaciones estructurales de un cuarto de siglo, R. Franco, A. León y R. Atria (coords.), Santiago, Comisión Económica para América Latina y el Caribe (CEPAL)/LOM Ediciones.

Erikson, R. y J. H. Goldthorpe (1992), The Constant Flux: A Study of Class Mobility in Industrial Societies, Oxford, Clarendon Press.

Espinoza, V. (2006), "La movilidad ocupacional en el Cono Sur. Oportunidades y desigualdad social", Revista de Sociología, № 20, Santiago, Universidad de Chile.

Espinoza, V., E. Barozet y M. L. Méndez (2013), "Estratificación y movilidad social bajo un modelo neoliberal: el caso de Chile", Lavboratorio, № 25, Buenos Aires.

Franco, R., M. Hopenhayn y A. León (2011), "Crece y cambia la clase media en América Latina: una puesta al día”, Revista CEPAL, № 103 (LC/G.2487-P), Santiago, Comisión Económica para América Latina y el Caribe (CEPAL).

(2010), Las clases medias en América Latina, Ciudad de México, Siglo XXI/Comisión Económica para América Latina y el Caribe (CEPAL).

Franco, R. y A. León (2010), "Clases medias latinoamericanas: ayer y hoy", Estudios Avanzados, №13, Santiago, Universidad de Santiago de Chile.

Gayo, M., M. L. Méndez y B. Teitelboim (2016), "La terciarización en Chile. Desigualdad cultural y estructura ocupacional”, Revista CEPAL, № 119 (LC/G.2683-P), Santiago, Comisión Económica para América Latina y el Caribe (CEPAL).

Gayo, M., B. Teitelboim y M. L. Méndez (2013), "Exclusividad y fragmentación: los perfiles culturales de la clase media en Chile", Universum, vol. 1, № 28 [en línea] http://dx.doi.org/10.4067/S0718-23762013000100006.

Gubbay, J. (2000), "Shifting classes: interactions with industry and gender shifts in the 1980s", Sociological Research Online, vol. 5, № 3, SAGE.

Hopenhayn, M. (2010), "Clases medias en América Latina: sujeto difuso en busca de definición", Clases medias y desarrollo en América Latina (LC/L.3240), A. Bárcena y N. Serra (eds.), Santiago, Comisión Económica para América Latina y el Caribe (CEPAL)/Fundación CIDOB.

Jorrat, J. R. (2005), "Aspectos descriptivos de la movilidad intergeneracional de clase en Argentina: 2003-2004", Lavboratorio, año 7, № 17/18, Buenos Aires.

Kaya, Y. (2008), "Proletarianization with polarization: industrialization, globalization, and social class in Turkey, 1980-2005", Research in Social Stratification and Mobility, vol. 26, № 2, Amsterdam, Elsevier.

Klein, E. y V. Tokman (2000), "La estratificación social bajo tensión en la era de la globalización", Revista de la CEPAL, № 72 (LC/G.2120-P), Santiago, Comisión Económica para América Latina y el Caribe (CEPAL).

Koo, H. (1990), "From farm to factory: proletarianization in Korea", American Sociological Review, vol. 55, $N^{\circ}$ 5, Washington, D.C., Asociación Estadounidense de Sociología.

Leiulfsrud, H., I. Bison y H. Jensberg (2005), "Social Class in Europe. European Social Survey 2002/3" [en línea] https://www.europeansocialsurvey.org/docs/methodology/ESS1_social_class.pdf.

León, A. y J. Martínez (2007), "La estratificación social chilena hacia fines del siglo XX", Estratificación y movilidad social en América Latina. Transformaciones estructurales de un cuarto de siglo, R. Franco, A. León y R. Atria (coords.), Santiago, Comisión Económica para América Latina y el Caribe (CEPAL)/ LOM Ediciones.

- (1987), Clases y clasificaciones sociales. Investigaciones sobre la estructura social chilena, 1970-1983, Santiago, Centro de Estudios del Desarrollo.

Li, J. H. y J. Singelmann (1999), "Social mobility among men: a comparison of neo-Marxian and Weberian class models", European Sociological Review, vol. 15, № 1, Oxford, Oxford University Press.

López-Calva, L. F. y E. Ortiz-Juárez (2014), "A vulnerability approach to the definition of the middle class", The Journal of Economic Inequality, vol. 12, № 1, Springer.

Lora, E. y J. Fajardo (2013), "Latin American middle classes: the distance between perception and reality", Economía, vol. 14, N 1, Washington, D.C., Brookings Institution Press.

Mallet, S. (1975), The New Working Class, Nottingham, Spokesman Books.

Marshall, G. y D. Rose (1988), "Proletarianization in the British class structure?", British Journal of Sociology, vol. 39, $N^{\circ} 4$, Wiley. 
Oesch, D. (2006), "Coming to grips with a changing class structure: an analysis of employment stratification in Britain, Germany, Sweden and Switzerland", International Sociology, vol. 21, N 2, SAGE.

Orellana, V. (2011), "Nuevos estudiantes y tendencias emergentes en la educación superior. Una mirada al Chile del mañana", Nueva geografía de la educación superior y de los estudiantes. Una cartografía del sistema chileno, su actual alumnado y sus principales tendencias, M. Jiménez y F. Lagos (eds.), Santiago, Ediciones Universidad San Sebastián.

Palomino, H. y P. Dalle (2012), "El impacto de los cambios ocupacionales en la estructura social de la Argentina: 2003-2011", Revista de Trabajo, vol. 8, № 10.

Pérez-Ahumada, P. (2017), "The end of a traditional class distinction in neoliberal society: 'white-collar' and 'blue-collar' work and its impact on Chilean workers' class consciousness", Critical Sociology, vol. 43, $N^{\circ}$ 2, SAGE.

Portes, A. y W. Haller (2004), "La economía informal", serie Políticas Sociales, № 100 (LC/L.2218-P), Santiago, Comisión Económica para América Latina y el Caribe (CEPAL).

Portes, A. y K. Hoffman (2003), "La estructura de clases en América Latina: composición y cambios durante la época neoliberal”, serie Políticas Sociales, № 68 (LC/L.1902-P), Santiago, Comisión Económica para América Latina y el Caribe (CEPAL).

PREALC (Programa Regional del Empleo para América Latina y el Caribe) (1978), Sector informal. Funcionamiento y políticas, Santiago, Organización Internacional del Trabajo (OIT).

Ruiz, C. y G. Boccardo (2015), Los chilenos bajo el neoliberalismo. Clases y conflicto social, Santiago, Nodo XXI/El Desconcierto.

Sen, Y.-S. y H. Koo (1992), "Industrial transformation and proletarianization in Taivvan", Critical Sociology, vol. 19, No 1, SAGE.

Solís, P. (2005), "Cambio estructural y movilidad ocupacional en Monterrey, México", Estudios Sociológicos, vol. 23, № 67, Ciudad de México, El Colegio de México.

Torche, F. (2014), "Intergenerational mobility and inequality: the Latin American case", Annual Review of Sociology, vol. 40.

(2005), "Unequal but fluid: social mobility in Chile in comparative perspective", American Sociological Review, vol. 70, N³, SAGE.

Touraine, A. (1971), The Post-Industrial Society. Tomorrow's Social History: Classes, Conflicts and Culture in the Programmed Society, Nueva York, Random House.

Weller, J. (2004), "El empleo terciario en América Latina: entre la modernidad y la sobrevivencia", Revista de la CEPAL, № 84 (LC/G.2258-P), Santiago, Comisión Económica para América Latina y el Caribe (CEPAL).

Wright, E. O. (1997), Class Counts: Comparative Studies in Class Analysis, Cambridge, Cambridge University Press. (1985), Classes, Londres, Verso.

Wright, E. O. y B. Martin (1987), "The transformation of the American class structure, 1960-1980", American Journal of Sociology, vol. 93, No 1, Chicago, The University of Chicago Press.

Wright, E. O. y J. Singelmann (1982), "Proletarianization in the changing American class structure", American Journal of Sociology, vol. 88, Chicago, The University of Chicago Press. 


\section{Anexo A1 \\ Construcción de cuadros de datos contrafactuales}

El cuadro 4 presentó el resumen de las fuentes de transformación de la estructura de clases chilena en los dos períodos analizados. Los valores de dicho cuadro se obtuvieron mediante la elaboración de dos cuadros de datos contrafactuales que muestran, con respecto a cada período en cuestión: i) los efectos asociados a la transformación de los sectores económicos y ii) los efectos derivados de los cambios en la composición de clases dentro de los sectores económicos. Estos cuadros se elaboraron siguiendo los pasos descritos por Wright y Singelmann (1982, págs. 202-205). Para fines expositivos, a continuación se explica en qué consisten dichos cuadros y la manera en que fueron hechos para el período de 2003 a 2013.

\section{Cuadro de datos contrafactuales para medir los efectos de la transformación de los sectores económicos}

Las columnas 1 y 2 del cuadro A1.1 exhiben las frecuencias observadas en cada categoría de clase en 2003 y 2013. La columna 3 indica el cambio esperado; es decir, cuánto debería haber crecido cada clase si lo hubiese hecho en la misma proporción en que aumentó el total de la población ocupada. Por ejemplo, en 2013 el tamaño de la población ocupada se incrementó un 22,86\% respecto de 2003. Así, la columna 3 muestra cuántas personas habría habido en cada clase si hubiera crecido un 22,86\%. Estas tres columnas son la base para la información de las columnas 5 (cambio observado), 6 (cambio esperado) y 7 (cambio neto, entendido como la resta entre el cambio observado y el esperado). La información de estas tres columnas se presentó íntegramente en las columnas I, II y III del cuadro 4.

La columna 4 del cuadro A1.1 corresponde al cambio de tamaño de las clases asociado a la transformación de los sectores económicos. Dicho cambio ponderado representa, en otras palabras, cómo habría sido, en 2013, la distribución de clases en cada uno de los 22 sectores económicos si, más allá del crecimiento o decrecimiento de esos sectores, la distribución de las clases dentro de ellos hubiera sido la misma de 2003. Esto se calculó ponderando el tamaño que cada sector económico tuvo en 2013 a partir de la distribución de clases observada en 2003. Los valores para cada clase corresponden, por tanto, a la suma de cada categoría de clase a través de los 22 sectores económicos utilizados en los cálculos. Sobre la base de lo anterior, la columna 8 presenta una medida específica para capturar el cambio en la estructura de clases resultante de la transformación de los sectores económicos. Dicho cambio se define como la resta entre el cambio ponderado (columna 4) y el cambio esperado (columna 3). De este modo, la columna 8 representa el crecimiento o decrecimiento del número de personas en cada categoría de clase si hubiera habido un cambio en los sectores económicos - controlado por el crecimiento de la población empleada-, pero no en la composición de clases dentro de dichos sectores. Los resultados de la columna 8 se presentaron íntegramente en la columna IV del cuadro 4.

Por último, la columna 9 del cuadro A1.1 muestra el número de personas que habría habido en cada clase social si solo hubiera existido un cambio en la composición de clases dentro de los sectores económicos más una transformación conjunta de la composición de clases y los sectores económicos (es decir, una interacción de ambos efectos). Dichos valores no están presentes en ninguna columna del cuadro 4 ya que no es posible interpretarlos en forma directa. Su información se debe complementar con los resultados del cuadro A1.2, que exhibe el efecto de los cambios en la composición de las clases y se presenta en el siguiente apartado. 
Cuadro A1.1

Chile: efecto de la transformación de los sectores económicos y cambios en la estructura de clases, 2003-2013

(En número de personas)

\begin{tabular}{|c|c|c|c|c|c|c|c|c|c|}
\hline & & Emp & leo & & & Cambio & & Causas c & lel cambio \\
\hline & 2003 & 2013 & $\begin{array}{c}\text { Esperado } \\
2013\end{array}$ & $\begin{array}{l}\text { Ponderado } \\
\text { según } \\
2003^{\mathrm{a}}\end{array}$ & Observado & Esperado & Neto & $\begin{array}{l}\text { Efecto de la } \\
\text { transformación } \\
\text { de los } \\
\text { sectores } \\
\text { económicos }\end{array}$ & $\begin{array}{c}\text { Efecto de la } \\
\text { transformación } \\
\text { en la } \\
\text { composición de } \\
\text { clases y efectos } \\
\text { de interacción }\end{array}$ \\
\hline Clase social & 1) & 2) & 3) & 4) & $\begin{array}{c}\text { 5) }= \\
2)-1)\end{array}$ & $\begin{array}{c}6)= \\
3)-1)\end{array}$ & $\begin{array}{c}\text { 7) }= \\
5)-6)\end{array}$ & 8) = 4) - 3) & $9)=2)-4)$ \\
\hline 1. Capitalistas & 50705 & 29106 & 62296 & 62734 & -21599 & 11591 & -33190 & 439 & -33628 \\
\hline $\begin{array}{l}\text { 2. Pequeños } \\
\text { empresarios }\end{array}$ & 176896 & 84840 & 217332 & 216876 & -92056 & 40436 & -132492 & -456 & -132036 \\
\hline $\begin{array}{l}\text { 3. Pequeña } \\
\text { burguesía }\end{array}$ & 302064 & 372109 & 371113 & 389709 & 70045 & 69049 & 996 & 18596 & -17600 \\
\hline $\begin{array}{l}\text { 4. Autoempleados } \\
\text { informales }\end{array}$ & 903190 & 1054839 & 1109649 & 999796 & 151649 & 206459 & -54810 & -109853 & 55043 \\
\hline 5. Gerentes & 81276 & 104560 & 99854 & 102080 & 23285 & 18579 & 4706 & 2225 & 2481 \\
\hline 6. Supervisores & 708075 & 947584 & 869933 & 928494 & 239510 & 161858 & 77652 & 58561 & 19091 \\
\hline 7. Expertos & 192922 & 271451 & 237022 & 271282 & 78528 & 44100 & 34428 & 34260 & 168 \\
\hline $\begin{array}{l}\text { 8. Clase } \\
\text { trabajadora }\end{array}$ & 3386332 & 4263120 & 4160410 & 4156638 & 876788 & 774078 & 102710 & -3772 & 106482 \\
\hline Total & 5801459 & 7127609 & 7127609 & 7127609 & 1326150 & 1326150 & & & \\
\hline
\end{tabular}

Fuente: Elaboración propia, sobre la base de datos de la Encuesta de Caracterización Socioeconómica Nacional (CASEN) (2003 y 2013) y la Encuesta Nacional de Empleo, Trabajo, Salud y Calidad de Vida de los Trabajadores y Trabajadoras de Chile (ENETS) (2009-2010).

a Ponderado por la composición de clases dentro de cada sector económico en 2003.

\section{Cuadro de datos contrafactuales para medir los efectos del cambio en la composición de clases dentro de los sectores económicos}

Las primeras tres columnas del cuadro A1.2 presentan la misma información que las columnas correspondientes del cuadro recién descrito. No ocurre lo mismo en el caso de la columna 4, que muestra cómo habrían cambiado las clases si no hubiera habido una transformación de los sectores económicos, es decir, si solo la distribución de clases dentro de ellos hubiera cambiado. Matemáticamente, esto se obtiene calculando el tamaño que los sectores económicos habrían tenido en 2013 si cada uno de ellos hubiera continuado absorbiendo la misma proporción de fuerza de trabajo que en 2003. Luego, sobre la base de esos totales esperados para cada sector económico, se calculó el tamaño de cada clase dentro ellos a partir de los porcentajes observados en 2013 -o sea, asumiendo que la composición de clases sí cambió tal como lo hizo-. Con ello se pudo cuantificar el cambio del tamaño de las clases suponiendo, al mismo tiempo, que la estructura de los sectores económicos fue igual en 2013 que en 2003. Como en el caso anterior, los valores de la columna 4 dieron origen a los de la columna 8 , que representa el efecto de la transformación de la composición de clases si se descuenta el crecimiento de la población empleada. Esos valores se presentaron íntegramente en la columna $\mathrm{V}$ del cuadro 4. 


\section{Cuadro A1.2}

Chile: efecto de la transformación en la composición de clases y cambios en la estructura de clases, 2003-2013

(En número de personas)

\begin{tabular}{|c|c|c|c|c|c|c|c|c|c|}
\hline & \multicolumn{4}{|c|}{ Empleo } & \multicolumn{3}{|c|}{ Cambio } & \multicolumn{2}{|c|}{ Causas del cambio } \\
\hline & 2003 & 2013 & $\begin{array}{c}\text { Esperado } \\
2013\end{array}$ & $\begin{array}{l}\text { Ponderado } \\
\text { según } \\
2003^{\mathrm{a}}\end{array}$ & Observado & Esperado & Neto & $\begin{array}{l}\text { Efecto de la } \\
\text { transformación } \\
\text { en la } \\
\text { composición } \\
\text { de clases }\end{array}$ & $\begin{array}{l}\text { Efecto de la } \\
\text { transformación } \\
\text { de los sectores } \\
\text { económicos } \\
\text { y efectos de } \\
\text { interacción }\end{array}$ \\
\hline & 1) & 2) & 3) & 4) & 5) = 2) - 1) & 6) = 3) - 1) & 7) = 5) -6$)$ & 8) = 4) - 3) & $9)=2)-4)$ \\
\hline 1. Capitalistas & 50705 & 29106 & 62296 & 27880 & -21599 & 11591 & -33190 & -34416 & 1226 \\
\hline $\begin{array}{l}\text { 2. Pequeños } \\
\text { empresarios }\end{array}$ & 176896 & 84840 & 217332 & 84938 & -92056 & 40436 & -132492 & -132395 & -98 \\
\hline $\begin{array}{l}\text { 3. Pequeña } \\
\text { burguesía }\end{array}$ & 302064 & 372109 & 371113 & 345096 & 70045 & 69049 & 996 & -26016 & 27013 \\
\hline $\begin{array}{l}\text { 4. Autoempleados } \\
\text { informales }\end{array}$ & 903190 & 1054839 & 1109649 & 1176731 & 151649 & 206459 & -54810 & 67082 & -121892 \\
\hline 5. Gerentes & 81276 & 104560 & 99854 & 102156 & 23285 & 18579 & 4706 & 2302 & 2404 \\
\hline 6. Supervisores & 708075 & 947584 & 869933 & 888648 & 239510 & 161858 & 77652 & 18715 & 58937 \\
\hline 7. Expertos & 192922 & 271451 & 237022 & 237273 & 78528 & 44100 & 34428 & 251 & 34178 \\
\hline $\begin{array}{l}\text { 8. Clase } \\
\text { trabajadora }\end{array}$ & 3386332 & 4263120 & 4160410 & 4264887 & 876788 & 774078 & 102710 & 104477 & -1768 \\
\hline Total & 5801459 & 7127609 & 7127609 & 7127609 & 1326150 & 1326150 & & & \\
\hline
\end{tabular}

Fuente: Elaboración propia, sobre la base de datos de la Encuesta de Caracterización Socioeconómica Nacional (CASEN) (2003 y 2013) y la Encuesta Nacional de Empleo, Trabajo, Salud y Calidad de Vida de los Trabajadores y Trabajadoras de Chile (ENETS) (2009-2010).

a Ponderado por la estructura de los sectores económicos en 2003.

Los valores de la columna 8 de este cuadro también sirvieron para aislar el efecto de interacción presentado en la columna 9 del cuadro A1.1. Como se señaló, dicha columna muestra el efecto de la transformación de la composición de clases más el efecto de la interacción entre los cambios de las clases y los sectores económicos. El efecto de interacción "puro" se calculó, por tanto, a partir de la resta entre dichos valores (columna 9 del cuadro A1.1) y los de la columna 8 del cuadro A1.2 (Wright y Singelmann, 1982, pág. 205). Tal efecto de interacción "puro" se presentó en la columna VI del cuadro 4. 